James F. Mayhew mD, Denis L. Bourke MD, Walter S. Guinee MD

\title{
Evaluation of the premature infant at risk for postoperative complications
}

\begin{abstract}
We reviewed anaesthetic records of 35 infunts with a hisiory of premalurity, who presenied for elective herniorrhaphy. We applied a scoring system to help evaluate risk of postoperative complications. Six patients experienced postoperative complications. All six patients had a scare of five or more and gave history of either apnoes or a history of moderate bronchopulmonary dysplasia. A preoperative history of apnoea andior moderate bronchopulmonary dysplasia appear to be valuable markers for postoperative complicalions. A conceptual age of 40 weeks is an acceptable lower limit of age providing there is no history of apmoea or pulmonary disease.
\end{abstract}

The incidence of congenital inguinal hernia in the premature infant has been reported to be 42 to 55 per cent. ${ }^{1,2}$ Reports suggest that premature infants have an increased risk of post anaesthetic complications when compared to full-term infants undergoing similar surgery. ${ }^{3-5}$ This is a review of our experience with premature infants who presented for elective herniorrhaphy. We also report an evaluation of a clinical scoring system for predicting the risk of postanaesthetic complications in this population.

\section{Methods}

With the approval of the Human Research Advisory Committee at the University of Arkansas for Medical Sciences, we retrospectively reviewed the records of 35 premature infants who had undergone elective inguinal herniorthaphy from January 1983 to January 1985. In

\section{Key words}

INFANTS: premature; COMPLICATIONS: postoperative; ANAESTHESIA: premature infant.

From the Department of Anesthesiology, Arkansas Children's Hospital, Little Rock, Arkansas.

Address correspondence to: Dr. James F. Mayhew, City of Faith Medical and Research Center, Department of Anesthesiology, 8181 South Lcwis, Tulsa, Oklahoma 74136. reviewing the charts, each patient was evaluated and assigned a risk number using a premature risk score suggested by $\mathrm{Oh}^{6}$ (Table I).

We defined apnoeic spells as the cessation of breathing for longer than 20 seconds, or for a shorter period if associated with bradycardia and/or cyanosis. A history of apnoea was defined as an apnoeic episode occurring between birth and the time of anaesthesia that required either stimulation or full resuscitation to restore breathing. Moderate apnoeic spells were defined as less than two spells in the four-week period prior to anaesthesia. Severe apnoea spells were defined as two or more such episodes in the four-week period prior to anaesthesia. Moderate bronchopulmonary dysplasia (BPD) was defined as presence of $x$-ray evidence of bronchopulmonary dysplasia without a history of medical treatment. Severe BPD was defined as that requiring medication.

The anaesthetic record was reviewed for anaesthetic techniques and intraoperative problems which would have an influence on postoperative complications. The record for the postoperative period was examined for complications, looking specifically for respiratory and/or cardiac complications, and feeding difficulties.

The premature risk score versus the presence/absence of postoperative complications was analyzed using the Spearman correlation coefficient.

Additionally, we applied the Fisher exact probability tcst, dividing the patients into two groups: those with scores of four or less and those with scores of five or greater.

The following modifications were made to the scores suggested by $\mathrm{Oh}^{6}{ }^{6}$ In the original scoring system, gestational age in weeks was used at time of surgery. We modified this by looking also at the gestational age, plus the postnatal age. We found that by using the conceptual age (gestational age plus postnatal age) at surgery, we had a better estimate of age as a risk factor, since an infant with a gestational age of 28 to 30 weeks would weigh the score toward a higher risk level, but when the conceptual age is considered (gestatioal age plus postnatal age), the severity of the prematurity becomes a less significant factor. Thus, three patients had a gestational age of 28 
IABLE I Anaesthetic risk score-premature infants*

\begin{tabular}{llll}
\hline Score & 0 & 1 & 2 \\
\hline Apnoeic spells & None & Moderate & Severe \\
Birh weight (gm) & $>2,500$ & $1,500-2,500$ & $<1,500$ \\
Gestational age (wk) & $>37$ & $30-36$ & $<30$ \\
Haemoglobin (gm\%) & $>12$ & $10-12$ & $<10$ \\
$\begin{array}{l}\text { Pulmonary disease } \\
\text { (bronchopulmonary }\end{array}$ & None & Moderate & Severe \\
dysplasia) & & & \\
\hline
\end{tabular}

*From Oh.6

weeks and one a gestational age of 26 weeks, but had conceptual ages of 45 to 60 weeks. These patients had no complications, despite a higher weighted score (Table IV). Of the patients with complications, three patients had a gestational age of 28 weeks, but had conceptual ages of
37 to 41 weeks. One patient had a conceptual age of 72 weeks.

\section{Results}

All the infants in the study were inpatients. They were permitted clear oral fluids up to three hours prior to surgery, and no patient received premedication. All infants received nitrous oxide, oxygen and halothane (Table II). In addition, four received isoflurane after an induction with halothane. No infant recejved intraoperative narcotics. Seven infants received a neuromuscular blocking drug, pancuronium. All induction techniques included a mask induction using nitrous oxide/oxygen and halothane following which the trachea was intubated and the lungs ventilated mechanically. Following completion of the surgical procedure, the infants were

TABLE II Summary results

\begin{tabular}{|c|c|c|c|c|c|c|c|c|c|c|c|}
\hline \multirow[b]{2}{*}{ Patient } & \multicolumn{3}{|c|}{ Ages } & \multicolumn{6}{|c|}{ Drugs daring anaesthesia } & \multirow[b]{2}{*}{ Score } & \multirow{2}{*}{$\begin{array}{l}\text { Post-Operative } \\
\text { Complications }\end{array}$} \\
\hline & $G A$ & $P N$ & $C N$ & $\mathrm{~N}_{2} \mathrm{O}$ & Halothane & Isoflarane & Pancuronium & Arropine & Meortigmine & & \\
\hline 1 & 33 & 20 & 53 & + & + & - & - & - & - & -3 & \\
\hline 2 & 36 & 9 & 45 & + & + & - & - & - & - & -3 & \\
\hline 3 & 30 & 46 & 76 & + & + & - & - & - & - & -4 & \\
\hline 4 & 33 & 43 & 76 & + & + & - & - & - & - & -4 & \\
\hline 5 & 33 & 12 & 45 & + & + & - & - & - &.- & -4 & \\
\hline 6 & 33 & 11 & 44 & + & + & - & - & & & -3 & \\
\hline 7 & 33 & 12 & 45 & + & + & + & - & - & - & -3 & \\
\hline 8 & 33 & 6 & 39 & + & + & - & - & - & - & -3 & \\
\hline 9 & 33 & 8 & 41 & + & + & + & - & - & - & -3 & \\
\hline 10 & 34 & 36 & 70 & + & + & + & - & - & - & -5 & \\
\hline 11 & 33 & 6 & 39 & + & + & + & - & - & - & -4 & \\
\hline 12 & 30 & 26 & 56 & + & + & + & - & - & - & -3 & \\
\hline 13 & 33 & 6 & 39 & + & - & + & - & - & - & -3 & \\
\hline 14 & 33 & 8 & 41 & + & + & + & - & - & - & -3 & \\
\hline $15^{* *}$ & 28 & 44 & 72 & + & + & + & + & + & + & -7 & Apnoea-ventilation \\
\hline $16^{* t}$ & 28 & 4 & 32 & + & + & + & + & + & + & -7 & Apnoca-ventilation \\
\hline 17 & 36 & 10 & 46 & + & + & + & - & - & - & -3 & \\
\hline 18 & 36 & 6 & 42 & + & + & + & - & - & - & -4 & \\
\hline 19 & 26 & 34 & 60 & + & + & + & - & - & - & -4 & \\
\hline $20 * \div$ & 33 & 10 & 43 & + & + & + & + & + & + & -6 & Apnoca-ventilation \\
\hline 217 & 28 & 9 & 37 & + & + & + & - & - & - & -5 & Asp. first feeding \\
\hline 22 & 31 & 8 & 39 & + & + & + & - & - & - & -3 & \\
\hline 23 & 34 & 44 & 78 & + & + & + & - & - & - & -4 & \\
\hline 24 & 34 & 40 & 74 & + & + & + & - & - & - & -5 & \\
\hline 25 & 36 & 6 & 42 & + & + & + & - & - & - & -4 & \\
\hline 26 & 36 & 11 & 47 & + & + & + & - & - & - & -3 & \\
\hline 27 & 28 & 17 & 45 & + & + & + & $m$ & - & - & -5 & \\
\hline 28 & 30 & 14 & 44 & + & - & - & + & + & + & -4 & \\
\hline 29 & 32 & 9 & 41 & + & + & + & - & - & - & -5 & \\
\hline $30^{*}$ & 29 & 7 & 36 & + & + & + & + & + & + & -6 & Apnoea-ventilation \\
\hline 31 & 30 & 8 & 38 & $t$ & + & + & + & + & + & -4 & \\
\hline 32 & 34 & 6 & 40 & + & + & + & - & - & - & -4 & Asp. first Feeding \\
\hline 33 & 28 & 20 & 48 & + & + & + & - & - & - & -5 & \\
\hline 34 & 28 & 24 & 52 & + & + & + & - & - & - & -4 & \\
\hline 35 & 32 & 9 & 41 & + & + & + & + & + & + & -4 & \\
\hline
\end{tabular}

GA - Gestational Age; PN - Postnatal Age; CN - Conceptual Age.

Apnoea. TBPD. 
TABLE III Risk scoress. Patients with complications

\begin{tabular}{|c|c|c|c|c|c|c|c|}
\hline \multirow[b]{2}{*}{ Patient } & \multicolumn{5}{|l|}{ Scores } & \multirow[b]{2}{*}{$\begin{array}{l}\text { Total } \\
\text { score }\end{array}$} & \multirow[b]{2}{*}{ Complications } \\
\hline & Apnoea & Birth wt. & $\begin{array}{l}\text { Gestationa! } \\
\text { age/surgery }\end{array}$ & $H_{g} b$. & Pulmonary & & \\
\hline 15 & $\mathbf{I}$ & 2 & 2 & 1 & I & $?$ & Apnoea-postop. ventilation \\
\hline 16 & 1 & 2 & 2 & I & l & 7 & Apnoea-postop. ventilation \\
\hline 20 & 1 & 2 & 1 & 1 & 1 & 6 & Apnoca-postop. ventilation \\
\hline 21 & 0 & 2 & 2 & I & 1 & 6 & Aspirated first feeding \\
\hline 30 & 1 & 1 & 2 & 1 & 1 & 6 & Apnoea-postop. ventilation \\
\hline 32 & 0 & 1 & 1 & 1 & 1 & 4 & Aspirated first feeding \\
\hline
\end{tabular}

permitted to breathe 100 per cent oxygen through the endotracheal tube until the infant had sustained spontaneous respirations and the vital signs remained within acceptable limits. Immediately following extubation the infants were given 100 per cent oxygen. All infants who had received a neuromuscular blocking agent had the agent reversed with atropine and neostigmine at the completion of surgery. The adequacy of the reversal was judged by the leg lift, as described by Mason. ${ }^{7}$ All infants were then cared for in an intermediate care unit. Their cardiac and pulmonary functions were monitored using an electrocardiograph and an apnoea monitor for at least 24 hours.

Table III lists the scores and complications. Table IV lists the scores of the patients with no postoperative complications.

Among the 35 infants, one patient had an intraoperative problem consisting of complete heart block immediately following the administration of the neostigmine. This was corrected by the administration of additional atropine. There was no postoperative complication related to this problem. Among the anaesthetic techniques and agents,

TABLE IV Risk scores. Patients with no complications

\begin{tabular}{|c|c|c|c|c|c|c|c|c|c|}
\hline Patient & Apnoea & Birth wt. & $\begin{array}{l}\text { Gestational } \\
\text { age/surgery }\end{array}$ & $\mathrm{Hg} b$ & Pulmonary & $\begin{array}{l}\text { Gestational age } \\
\text { surgery (weeks) }\end{array}$ & $\begin{array}{l}\text { Conceptual } \\
\text { age }\end{array}$ & $\begin{array}{l}\text { Wt.lsurgery } \\
(k g)\end{array}$ & Total score \\
\hline 1 & 0 & 1 & 1 & 1 & 0 & 33 & 53 & 7.0 & 3 \\
\hline 2 & 0 & 1 & 1 & 1 & 0 & 36 & 45 & 3.7 & 3 \\
\hline 3 & 0 & 2 & 1 & 1 & 0 & 30 & 76 & 3.2 & 4 \\
\hline 4 & 0 & 2 & I & 1 & 0 & 33 & 76 & 3.7 & 4 \\
\hline 5 & 0 & 2 & 1 & 1 & 0 & 33 & 45 & 3.3 & 4 \\
\hline 6 & 0 & 1 & 1 & 1 & 0 & 33 & 45 & 3.7 & 3 \\
\hline$\tau$ & 0 & 1 & 1 & 1 & 0 & 33 & 45 & 4.1 & 3 \\
\hline 8 & 0 & 1 & 1 & 1 & 0 & 33 & 39 & 4.8 & 3 \\
\hline 9 & 0 & 1 & 1 & 1 & 0 & 33 & 41 & 3.8 & 3 \\
\hline 10 & 0 & 2 & 1 & 2 & 0 & 34 & 70 & 2.5 & 5 \\
\hline 11 & 0 & 2 & 1 & 1 & 0 & 33 & 39 & 1.6 & 4 \\
\hline 12 & 0 & 1 & 1 & 1 & 0 & 30 & 56 & 4.0 & 3 \\
\hline 13 & 0 & 0 & 2 & I & 0 & 33 & 39 & 4.6 & 3 \\
\hline 14 & 0 & 1 & 1 & 1 & 0 & 33 & 41 & 4.6 & 3 \\
\hline 17 & 0 & 1 & I & 1 & 0 & 36 & 46 & 4.5 & 3 \\
\hline 18 & 0 & 1 & 1 & 2 & 0 & 36 & 42 & 3.0 & 4 \\
\hline 19 & 0 & 2 & 1 & 1 & 0 & 26 & 60 & 2.8 & 4 \\
\hline 22 & 0 & 1 & 1 & 1 & 0 & 31 & 39 & 1.5 & 3 \\
\hline 23 & 0 & 2 & 1 & 1 & 0 & 34 & 78 & 4.8 & 4 \\
\hline 24 & 0 & 2 & 2 & 1 & 0 & 34 & 74 & 2.0 & 5 \\
\hline 25 & 0 & 1 & 2 & 1 & 0 & 36 & 42 & 3.0 & 4 \\
\hline 26 & 0 & 1 & 1 & 1 & 0 & 36 & 47 & 2.8 & 3 \\
\hline 27 & 0 & 2 & 2 & 1 & 0 & 28 & 45 & 3.7 & 5 \\
\hline 28 & 0 & 2 & 2 & 0 & 0 & 30 & 44 & 4.1 & 4 \\
\hline 29 & 0 & 2 & 2 & 1 & 0 & 32 & 41 & 2.6 & $\mathbf{5}$ \\
\hline 31 & 0 & 2 & 2 & 2 & 0 & 28 & 48 & 3.4 & 6 \\
\hline 33 & 0 & 2 & 2 & 0 & 0 & 28 & 52 & 3.1 & 4 \\
\hline 34 & 0 & 2 & 2 & 0 & 0 & 32 & 41 & 3.2 & 4 \\
\hline 35 & 0 & 0 & 2 & 2 & 0 & 32 & 41 & 3.6 & 4 \\
\hline
\end{tabular}


TABLE $\mathrm{V}$ Weights at time of surgery $(\mathrm{kg})$

\begin{tabular}{ll}
\hline No complication group (29) & Complication group (6) \\
\hline Range $1.5-7.0$ & 1.8 to 3.1 \\
Mean 3.58 & 2.2 \\
SEM \pm 0.24 & SEM \pm 0.15 \\
\hline
\end{tabular}

$p<0.01$

only the use of a nondepolarizing muscle relaxant pancuronium was associated with an increased incidence of postoperative complications. Of the six patients who developed postoperative complications, four had received the pancuronium and needed postoperative ventilatory support. Three of the 29 patients without complications had received pancuronium and needed no postoperative ventilatory support.

Using the Spearman correlation coefficient, the association between the premature score and complications was $\mathfrak{r}_{\mathfrak{q}}=0.59$ and $p<0.001$. Among the individual risk factors the history of pulmonary disease and apnoea episodes correlated with postoperative complications.

Applying the Fisher's exact test, we were able to divide out patients into two groups; anaesthetic risk scores of five or greater was associated with a significant higher incidence of postoperative complications and those of four or less was associated with a noncomplicated postoperative course $(p<0.0001)$

We also looked at the weight at time of surgery. The range of weight for the complicated group was 1.8 to $3.1 \mathrm{~kg}$ with a mean of $2.2 \pm 0.15$ (SEM). The range for the noncomplication group was 1.5 to $7 / 0 \mathrm{~kg}$ with a mean of $3.5 \pm 0.24$ (Table V). Using Student's t test $p<0.01$.

\section{Discussion}

In 1982 Steward $^{3}$ wamed of the high incidence of postoperative complications in the premature infant. Since then at least one additional report of postoperative complications in this population has appeared. ${ }^{4}$

Although thesc infants may present with a post-birth age of three to four months, they may remain premature when their conceptual age is considered. Wellborne et al. ${ }^{5}$ used an evaluation system of postnatal age, weight and perinatal history consisting of apnoea spells, sudden infant death syndrome in the family, respiratory distress syndrome, bronchopulmonary dysplasia, seizures and pneumonia. Infants with a score greater than nine and a postnatal age of less than 44 weeks had periodic breathing postoperatively. However, in their series none had required postoperative respiratory support.

We found, as did Liu et al., ${ }^{4}$ that the use of nondepolarizing muscle relaxants was associated with an increase in postoperative complications. Of the 29 patients who had a score of four or less with no postoperative complications, three had received a nondepolarizing muscle relaxant, while four of the six who had had scores of five or higher had postoperative complications received a nondepolarizing muscle relaxant. All the infants in this series who had received a nondepolarizing muscle relaxant were judged to be adequately reversed by the criteria of Mason. ${ }^{6}$ In the report by Liu et al. ${ }^{4}$ four of six patients who had received a nondepolarizing muscle relaxant needed postoperative ventilatory support while two of seven who had a normal recovery received a nondepolarizing muscle relaxant. This is not explained in the report by Liu et al. ${ }^{4}$ and in review of our patients the infants who had received the muscle relaxants had the higher risk score; thus, it was determined to be the more ill infant who had received the muscle relaxant. It would appear that it was judged at the time that these infants could not tolerate the higher doses of halothane or isoflurane and thus the muscle relaxant was used as part of the anaesthetic regimen.

Several authors have suggested that elective surgery be avoided in children less than $44^{8}$ to $46^{4}$ weeks conceptual age. Ten of our patients, who had no complications, had conceptual ages below these suggested limits, while five of the six with complications had a conceptual age of less than 40 weeks. Review of the report by Liu et al. ${ }^{4}$ shows that none of their reported patients over 41 weeks of conceptual age had postoperative complications, provided there was no preoperative history of apnoea or pulmonary disease. As expressed by Liu at al. ${ }^{4}$ jdeally infants at risk for apnoeic episodes during recovery from anaesthesia should be identified prior to anaesthesia and surgery. A scoring system for assessing risk for postoperative complications in premature infants was designed to identify these infants. Our scoring system was modified to include both the gestational age and postnatal age defined as conceptual age as a factor. As we statistically evaluated the results we found that the haemoglobin and birth weight did not influence the risk factors and that only a history of apnoea and/or pulmorary disease were significant risk markers for postoperative complications.

When weight at the time of surgery was evaluated, we found that the weight of the noncomplication group was significantly higher than the weight in the complication group. However, our smallest infant was found in the group which had no complications. 


\section{References}

1 Harper $R G$, Garcia A, Sia $C$. Inguinal hernia: a common problem of premature infants $1000 \mathrm{gms}$ or less at birth. Pediatrics $1975 ; 56: 112-5$.

2 Rescaila $R J$. Grosfeld $J L$. Inguinal hemia repair in the perinatal period and early infancy: clinical considerations. J Ped Surg 1984; 19: 832-7.

3 Steward DJ. Preterm infants are more prone to complications following minor surgery than are term infants. Anesthesiology 1982; 56: 304-6.

4 Liu LMP, Cote CJ, Goudsouzion NG el al. Life-threatening apnea in infants recovering from anesthesia. Anesthesiology 1983; 59:506-10.

5 Welbourn LG, Ramirez $N$, Oh TH et al. Evalution of anesthetic risks in premature infants. Anesthesiology 1984 61: $A 417$.

$6 O h T H$. Inguinal hemia repair in premature infants. In: Common Problems in Pediatric Anesthesia. Stehling LC (ed.) Year Back Medical Publishers, Chicago, 1982.

7 Mason LJ, Betts EK. Leg lift and maximum inspiratory force, Clinical signs of neuromuscular blockade reversal in neonates and infants. Anesthesiology 1980; 52: 441-2.

8 Pascucci RC, Kurachehek SC, Kelly DH et al. Evaluation of respiratory patterns of infants in the perioperative period. Anesthesiology 1984, 61: 3A, A420.

9 Gregory G. Steward D. Life-threatening perioperative apnea in the "ex-premie." Anesthesiology 1983, 59: 495-8

\section{Résumé}

Nous avonts résumé les dossiers ariesthésiques de 35 patients ayant une anamnèse de prématurité et s'étant présentés pour une herniorraphie élective. Nows avons appliqué un système de pointage aidant à évaluer le risque de complications postopératoires. Six paticnts ont subi des complications postopératoires. Les six patients avaient un poinlage de cinq ou plus et une anamnèse d'apnée ou de dysplasie bronchopuimonaire modérée. L'apnée etlou la dysplasie bronchopulmonaire modérée contenues dans une anamnèse préopératoire semblent être des indicateur utiles de complications postopératoires. Un âge conceptuel de 40 semaines est la limite d'áge la plus basse qui soit acceptable pourvu qu'il n'y ait pas d' histoire d'apnée ou de maladie pulmonaire. 